\title{
Society of American Gastrointestinal and Endoscopic Surgeons (SAGES) grant impact on recipient academic career
}

\author{
Aurora D. Pryor · Basil M. Yurcisin · Sharon Bachman • \\ Atul Madan • Dimitrios Stefanidis • Alfonso Torquati • \\ SAGES Research and Career Development Committee
}

Received: 3 September 2009/Accepted: 9 November 2009/Published online: 29 December 2009

(C) The Author(s) 2009. This article is published with open access at Springerlink.com

\begin{abstract}
Introduction Surgical societies, including SAGES, distribute grant funds to support research, as well as to promote recipient careers. Although we hypothesize that these awards have a positive impact, no objective evidence exists. We sought to benchmark the scientific productivity of the grants, the academic success of the recipients, and the generation of further research projects.

Methods All SAGES grant principle investigators (PI) and co-PIs were surveyed using Survey Monkey ${ }^{\mathrm{TM}}$. Questions included resultant presentations/publications, ensuing funding, academic promotion, further research initiatives, and opinions on grant impact. A Medline query of all grant recipients was used to verify and supplement this data.

Results 48 of 108 recipients (44\%) responded to the survey, with $81 \%$ of respondents listed as the PI. The majority of the funded studies (73\%) were accepted for presentation at a national meeting, with $89 \%$ presented at SAGES and $9 \%$ receiving various meeting awards. Grant recipients attended 3.8 of the last 5 SAGES meetings. Respondents also reported a $64 \%$ rate of publication, with the majority published in Surgical Endoscopy (68\%). Of recipients, $84 \%$ had at least one publication identified by a Medline search, with an
\end{abstract}

A. D. Pryor $(\bowtie) \cdot$ B. M. Yurcisin · A. Torquati

Duke University Medical Center, 407 Crutchfield St., Durham,

NC 27704, USA

e-mail: Aurora.pryor@duke.edu

S. Bachman

University of Missouri, Columbia, MO, USA

\author{
A. Madan \\ Los Angeles, CA, USA \\ D. Stefanidis \\ Carolinas Medical Center, Charlotte, NC, USA
}

average of 32 papers since grant completion. Among the awardees, $43 \%$ received further research funding, most frequently (43\%) from a professional organization and occasionally (7\%) from the National Institutes of Health. The amount of extramural funding received was greater than US $\$ 50,000$ for $67 \%$ of the awardees, with half of those receiving more than US $\$ 200,000$.

Conclusion SAGES grants have a strong impact on recipient academic careers. Future funding, society activism, and publication are favorably influenced by these grants. SAGES should continue to support research with this successful mechanism as a necessary tool for the academic growth of recipients and development of research deemed important by SAGES.

Keywords Grant $\cdot$ Research $\cdot$ Funding $\cdot$ Career

Young physician-researchers are a dying breed due to many external stressors. Large medical training debt, difficulty obtaining funding and protected time for research, lucrative clinical opportunities, and uncertain success are just a few such deterrents [1]. Early success does not predict continuation of an academic career or successful funding for MD researchers [2]. Programs aimed at teaching research skills and providing financial support may help career development for young surgical scientists. Career advancement for an academic physician may rely heavily on their ability to generate funding for and subsequent publications from their research. Small seed grants and independent society awards, such as those from the Society of American Gastrointestinal and Endoscopic Surgeons (SAGES), seem to be very important supports for career development.

There is a shift in the current financing of basic and clinical research in the USA. Between 1998 and 2003, the 
National Institutes of Health budget doubled to US \$27.1 billion [3]. After peaking in 2004, the budget has been progressively cut in subsequent years. In 2008, the NIH budget fell 1.1\% compared with 2007 and continued to fall well behind its own calculations of biomedical research inflation $(\sim 3.7 \%)$. Based on these calculations, relatively the NIH budget fell $12 \%$ from 2004 to 2008 , and $8 \%$ based on economy-wide inflation [4]. This trend has led to increasing difficulty for researchers in obtaining funding from the NIH, for both first-time and renewing applicants. In 2000, renewing R01 applicants had a 53\% chance of acceptance on their first submission; this figure reduced to below $24 \%$ in 2008 [3]. Although new government sponsored initiatives, such as the US \$200 million available for "Challenge" grants from the NIH [5], may change these schemes in 2009, this has yet to be proven. The role of government funding of scientific research is likely to remain significant, however the importance of other sources of funding for research endeavors is still obvious.

Established researchers also feel the pressure to generate funds to continue their work. Frequently preliminary data are necessary to acquire government and large-value grants for new projects. Small start-up awards potentially help the development of new lines of research within the framework of a larger question. As a result, established investigators have increasingly turned to alternative resources to develop new lines of investigation. These funds allow the researcher to diversify their resources and can reduce the chance of loss of continuation of research, especially due to the expiration of a sole funding source. The current economic environment and the increasing difficulty in securing government funding for research projects underscores the need for professional organizations to continue seed money and grant programs.

Many professional organizations provide annual grant awards to support ongoing research in their field. The SAGES research grant program has been in existence since 1992, when two grants were distributed during the first year. Since then a total of 143 grants have been funded. Currently, seven to nine awards for up to US $\$ 30,000$ each are handed out annually. Since 2000, a total of US $\$ 1.44$ million has been awarded in SAGES grants. Despite awarding well over US \$1 million in grant funding since 2000, neither SAGES nor any other general surgical society has assessed the impact of their funded grants. This study set out to augment the paucity of data in regards to the true impact of surgical society grants on their recipients' academic careers. The objective of this study is to evaluate the impact of SAGES grants on the career of recipients through a survey of previous awardees. Our hypothesis was that recipients would perceive that obtaining a SAGES grant had a positive impact on their academic career.

\section{Methods}

All recipients, principle investigators (PIs) and co-PIs, of SAGES grants from 1992 to 2008 with available e-mail addresses were surveyed. The survey was generated using Survey Monkey ${ }^{\mathrm{TM}}$ [5]. Survey questions are shown in Table 1. After return of initial surveys, a second round of surveys was sent to those who did not respond during the first round. In total, 108 individuals were queried. The evaluation assessed the impact of the SAGES research grants in regards to: (1) completion/publication/presentation of proposed research, (2) academic advancement, (3) additional fund generation, and (4) professional society participation with special reference to SAGES. The answers to the survey were verified by reviewers, and a Medline search from the National Library of Medicine of all principle investigators was used to supplement survey responses and confirm publication data. Academic benefit of the grant award was assessed by recipient ability to generate further research funding. In addition, recipient opinions were pursued by asking them whether the grant assisted them in advancement within the academic community.

Reported publication data were verified by four reviewers via a Medline search from February to April 2009. To minimize reporting bias, a Medline search was also used to gather data from grant recipients who did not respond to the survey or for whom no contact information was available. The search aimed at identifying recipient publications (both grant related and total number) since the grant award. Reviewers sorted all Medline publications for each PI and compiled total publications/investigator, number of publications relevant to the specific funded

Table 1 Survey questions asked to grant recipients

- Year of grant funding/PI versus co-PI

- Were you the original applicant?

- Did you complete the proposed project? If no, why not?

- Did you present this work? Where? When? Award?

- Did you publish this work? Where? When? Reference

- Did this grant help you receive further funding? How much? From where?

- Have you published other papers in this area?

- Number of peer-reviewed papers you have published since receiving grant (any topic)?

- Academic rank at the time of grant receipt

- Current academic rank, or private practice?

- How many SAGES meetings have you attended in the last 5 years?

- How many times did you present at SAGES in the last 5 years?

- Did the SAGES grant help your career?

- Suggestions to make future SAGES grants more helpful? 
question, and total publications/investigator related to the grant topic (subsequent investigations).

\section{Results}

The response rate after two rounds of survey requests was $44 \%$ (48/108). Of those who completed the survey, $73 \%$ indicated that they had completed the project outlined in the grant proposal. Of those 15 projects reported incomplete, only $6(40 \%)$ were abandoned for various reasons. The other incomplete grants, including all incomplete studies since 2004, were all listed as still in progress. Not surprisingly, only 33\% of grants awarded in 2007 were complete at the time of the survey. A Medline search of all grant projects (independent of whether the survey was completed) between 1992 and 2003 was completed for 118 PIs. The Medline search verified self-reported data, indicating that $64 \%$ of recipients had published a manuscript on their grant topic, after the grant award. The average time from grant funding to publication was 2.6 years (range 07 years). Published and unpublished studies by year are shown in Fig. 1. Three-quarters of the Medline queried publications were published in Surgical Endoscopy (Fig. 2). A majority (73\%) of survey responders indicated that they had presented their findings at a scientific meeting (SAGES 89\%, American College of Surgeons 4\%, Digestive Disease Week 4\%, and other 4\%). Nine percent of respondents received an award for the presentation of their grant-funded work.

Among the awardees, $43 \%$ claimed that further research funding was impacted by the data generated by the SAGES grant. Subsequent funding greater than US \$50,000 was obtained by $67 \%$ of the awardees, with half of those receiving more than US $\$ 200,000$ in extramural funding. The most frequent extramural funding source was

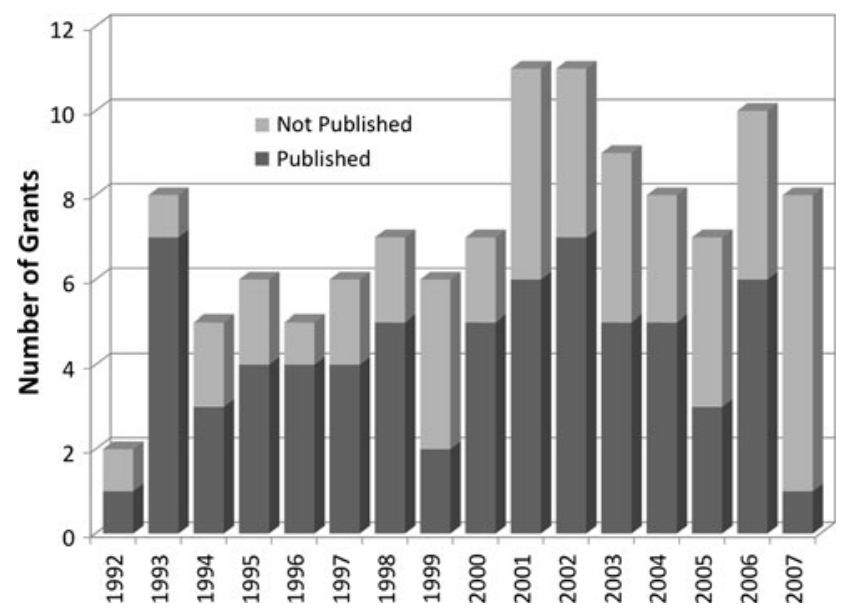

Fig. 1 Grants resulting in publication or no publication, based on award year; average time from grant award to publication is 2.6 years professional organizations $(43 \%)$, followed by industry $(14 \%)$, military $(7 \%)$, and the NIH $(7 \%)$.

Most recipients $(90 \%)$ indicated that the SAGES grant positively impacted their career. Of the five individuals who did not think the award furthered their career, two $(40 \%)$ did not complete their study. Four of five $(80 \%)$ did not generate any publications or presentations from their grant. One $(20 \%)$ believed it was too early to tell what impact the grant would have. The one presented and published study that was felt to be of no impact was awarded to a tenured associate professor who did receive further funding in the same area. The current academic status of the responders was as follows: $33 \%$ assistant professor, $21 \%$ associate professor, $8 \%$ full professor, $13 \%$ professor with tenure, $13 \%$ trainee, and $13 \%$ non-tenure-track faculty or private practice. After elimination of the trainees who have not yet started their careers, $85 \%$ of those responding were in academic medicine.

Responders remained involved with SAGES, as they had attended an average of 3.8 of the last 5 SAGES meetings and most $(81 \%)$ had presented at SAGES at least once in the last 5 years. Importantly, $43 \%$ of recipients had presented four or more times. Publications following the receipt of a grant were reported to be on average 20 (2150). Most grant recipients were confirmed to be productive in regard to publishing; a Medline search of the entire population showed that $84 \%(99 / 118)$ had at least 2 peerreviewed publications since the grant award, and these published recipients had an average of 32 papers (range 2373). Published recipients averaged 3.7 papers per year after the grant award. As confirmed by the Medline search, almost $50 \%$ of awardees published additional papers in the area of their grant project (57/118). Of these, the investigators on average published 9 related papers (range 0-200).

\section{Discussion}

Our data demonstrate that, in general, SAGES grant recipients have been quite successful in their academic careers after receiving the awards. The majority of awardees perceive that receiving the grant has helped their research endeavors. Furthermore, the grant recipients have been active in the society after receiving grants from SAGES. We have shown that most funded projects are completed, presented, and published within a reasonable time. On average, four out of ten recipients garner further funding. Eighty-five percent remain within academic medicine. These grants are an excellent vehicle to support and foster academic success in an era of tenuous funding.

It is a long-held belief that academic success begets academic success. Many societies look at prior publication and awards history when choosing grant recipients. It is 
Fig. 2 Distribution of published grant projects, by journal

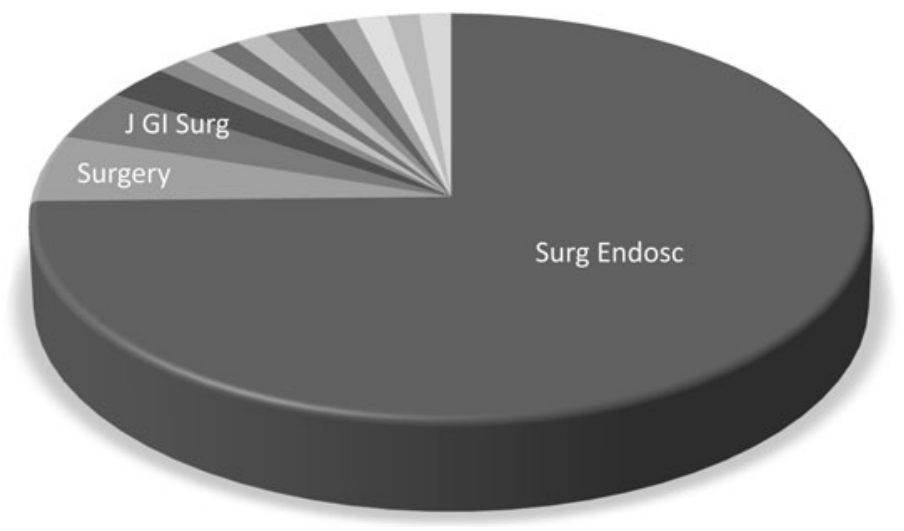

Surg Endosc

$\square$ Surgery

a J GI Surg

a Br J Surg

Am J Surg

$\square$ Am Surgeon

Arch Surg

$\square$ Chest

Clin Exp Metastasis - 2006

a JACS

Obes Surg

$\square$ Respir Res

Surg Clinics of N. America

$\square$ Surg Lap Endo Percutan Tech believed that, by supporting young investigators, agencies can encourage research in their respective field. This support also bolsters the young surgeon's academic career. These data from this study help support these thoughts.

Part of the SAGES mission is to foster, support, and encourage clinical and basic science research by increasing the number and quality of surgical investigators in this field. This goal is accomplished by encouraging young SAGES members to seek research funding, improve their grant-writing skills, and help establish them in a successful academic career.

The most compelling conclusion of the current study is the clear benefit to the funding society. Most grant recipients publish in the society journal, Surgical Endoscopy, and present their results at the SAGES annual meeting. This is appropriate as the recipients are required to submit their results to both as a completion requirement of their grant. Of note, recipients of SAGES grants stay active in the organization and have successful academic careers. After receiving the award, awardees have attended almost four of the last five SAGES meetings. Promising young scientists who receive these grants remain active participants in the programs of the funding agency.

Although our survey is the first to assess the impact of general surgical society grants on academic careers, there are several other grant assessment studies. The most recent and extensive study was a 25-year review of a gastroenterology grant program [6]. Through a grant database and literature review, those authors concluded that $69 \%$ of their 255 awardees published based on their grant-funded research. This mirrors our data. However, only $62 \%$ of their awardees remained in academic medicine. Crockett and colleagues do make some interesting conclusions on grant funding, demonstrating that higher award amounts, holding an advanced degree, and successful publication were associated with careers in academic gastroenterology.

A 2005 study reviewed the impact of NIH RO1 funded projects [7]. This study followed 18,211 projects funded in 1996 for a period of 4 years. These studies resulted in an average of 7.6 related Medline publications during this period. The authors demonstrated a higher publication rate for: competing renewals versus new grants, for basic science projects, for full professors, and for universities with graduate programs ranked in the top 10 by US News and World Report. These applicant criteria are important for NIH project evaluation and stress the importance of success with seed money projects, such as those supported through SAGES, in garnering NIH funding.

Several studies evaluated the impact of society seed grants [8-16]. These reviews all concluded that seed grants are effective for stimulating academic careers. From these reports, $12-71 \%$ of awarded projects were published. One demonstrated a $64 \%$ society-specific publication rate [16]. Subsequent funding was received by $28-74 \%$ of grant recipients. One study reported US $\$ 10$ in additional funding per US \$1 of seed money awarded [10]. Despite variability in study design, all concluded that small society grants are of benefit for academic career development.

A limitation of our current study is the difficulty delineating whether recipients would have been successful without the grants. If grant selection is appropriate, all awardees should demonstrate at least some individual academic promise or solid motivation and mentorship. In theory, those receiving grants already possess the skills important for successful academic careers. All funded grant projects are expected to be well planned and appropriate in scope for successful completion. In other words, we cannot be sure whether obtaining a SAGES grant is a cause or an effect of the academic careers. To truly determine the impact of these grants, a study would have to compare high-quality grant applications that are randomized to receiving funding or no funding. Obviously, such an investigation would be hard to justify ethically and logistically. Unfortunately, such a study would have the pre-existing bias of the grant review committee. Another limitation is that we did not have a $100 \%$ response rate and, despite the fact that we supplemented the data with Medline searches, this limitation introduces some selection bias into the study. It may be that those who did not respond would have felt that the grant support was not helpful to their career. 
In summary, we have demonstrated that SAGES grant recipients complete their projects and publish the results. In addition many garner further funding and most pursue successful academic careers. Society grants such as those awarded by SAGES allow young investigators to embark on successful research careers. Many use these grants to seed research projects leading to full careers as surgeoninvestigators. In the setting of limited government funding, such funding sources are essential and are regarded as such by recipients. The funding society also benefits by catching and keeping the interest of promising young investigators. These grants should be continued as an excellent avenue for fostering both research and interest in academic gastrointestinal and endoscopic surgery.

Acknowledgements The authors would like to thank Yumi Hori, Vanessa Cheung, and Jason Levine in the SAGES office for their help with the survey. We could not have offered the grants, nor completed the survey, without the support of the SAGES membership and board, as well as the financial support from the SAGES Foundation and the donors to the Foundation. We would also like to acknowledge the remainder of the SAGES Research and Career Development Committee for their commitment to and expert review and follow-up of the SAGES grants.

Disclosures Dr. Pryor is a consultant and speaker for Covidien and Olympus. She is a consultant for Gore, Transenterix, and Immersion. She has an ownership interest in Transenterix and Barosense. Covidien also provides research support. Dr. Yurcisin receives fellowship support from Covidien. Dr. Bachman receives salary support from Covidien, LifeCell, Musculoskeletal Transplant Foundation, Johnson and Johnson, and Ethicon for research studies. She has received gifts to her laboratory from WL Gore, Atrium, and Tissue Science Laboratories. She has also received honoraria for teaching from Bard/ Davol and Covidien. Dr. Madan has nothing to disclose. Dr. Stefanidis received honoraria from Davol, Gore, and Ethicon for lectures. Dr. Torquati is a consultant for Covidien.

Open Access This article is distributed under the terms of the Creative Commons Attribution Noncommercial License which permits any noncommercial use, distribution, and reproduction in any medium, provided the original author(s) and source are credited.

\section{References}

1. Goldhamer ME, Cohen AP, Bates DW, Cook EF, Davis RB, Singer DE et al (2009) Protecting an endangered species: training physicians to conduct clinical research. Acad Med 84:439-445
2. Dickler HB, Fang D, Heinig SJ, Johnson E, Korn D (2007) New physician-investigators receiving National Institutes of Health research project grants: a historical perspective on the "endangered species". JAMA 297:2496-2501

3. Wadman M (2009) Research funding: closing arguments. Nature 457:650-655

4. Available from: www.aaas.org [cited May 3, 2009]

5. Available from: http://grants.nih.gov/grants/guide/rfa-files/RFA -OD-09-003.html [cited May 3, 2009]

6. Crockett SD, Dellon ES, Bright SD, Shaheen NJ (2009) A 25year analysis of the American College of Gastroenterology research grant program: factors associated with publication and advancement in academics. Am J Gastroenterol 104(5):10971105

7. Druss BG, Marcus SC (2005) Tracking publication outcomes of National Institutes of Health grants. Am J Med 118:658-663

8. Cunningham BL, Landis GH (1993) A study of the outcome of the American Society for Aesthetic Plastic Surgery research grant program. Plast Reconstr Surg 92:1397-1401

9. Fung C, Hitchcock M, Fisher D (2005) Effects of funding family physicians for advanced research training. Fam Med 37:434-439

10. Hanson CS, Schneider D, Hill AM (2008) Seed grants as a means of stimulating cancer research funding. Health Policy 88:243-249

11. Keil MF, Lipman TH (2007) Outcomes associated with 12 years of grant funding: the Pediatric Endocrinology Nursing Society grant program. J Pediatr Nurs 22:166-168

12. Mahoney MC, Verma P, Morantz S (2007) Research productivity among recipients of AAFP foundation grants. Ann Fam Med 5:143-145

13. Miller DR, Wozny D (2007) Research awards program of the Canadian Anesthesiologists' Society/Canadian Anesthesia Research Foundation: survey of past recipients. Can J Anaesth 54:314-319

14. Paller MS, Cerra FB (2006) Investing in research: the impact of one academic health center's research grant program. Acad Med 81:520-526

15. Rose RC, Prozialeck WC (2003) Productivity outcomes for recent grants and fellowships awarded by the American Osteopathic Association Bureau of Research. J Am Osteopath Assoc 103:435-440

16. Young KD (2008) Productivity and career paths of previous recipients of Society for Academic Emergency Medicine research grant awards. Acad Emerg Med 15:560-566 